\title{
Elevada mortalidade entre pacientes com diagnóstico de neoplasia estabelecido em ambulatório de pronto- atendimento clínico - Estudo IMACS
}

\author{
Hamerski, S.; Hoppe, P.; Hoffmeister, E.; Azeredo-Da-Silva, A.L.F.; \\ Apresentador: Silvana Hamerski
}

\section{Resumo}

Introdução: A procura dos serviços de urgência e de emergência por pacientes portadores de neoplasia esteja em elevação devido à elevação na incidência de neoplasias na população. São escassos os estudos que busquem quantificar e descrever essa demanda. Métodos: Estudo de coorte retrospectivo. Foram revisados 922 consultas do ambulatório de pronto-atedimento (PMI) no período de julho a novembro de 2011, sendo obtidas informações sócio-demográficas e clínicas. Os casos foram classificados em 2 grupos: Grupo1-pacientes com diagnóstico de neoplasia como doença de base, que procuraram o PMI em razão de queixas clínicas de qualquer natureza e Grupo2-pacientes que procuraram o PMI por queixas clínicas que resultaram no estabelecimento do diagnóstico de neoplasia no pronto-atendimento. A mortalidade foi aferida após um seguimetno médio de 2 anos, restrito ao registro do prontuário eletrônico. Foram utilizados os softwares Epi-Info v3.5.2 e PASW v18.0. O estudo obteve aprovação ética (GPPG 11-0451). Resultados: Entre as 922 consultas de pronto-atendimento avaliadas, foram identificados 73 pacientes $(7,9 \%)$ com diagnóstico de neoplasia: 51 (5,5\%) classificados como grupo1 e $22(2,4 \%)$ como grupo2. Entre os pacientes do grupo1, a média de idade foi de 63,7 anos, $52,8 \%$ eram do sexo masculino, $66 \%$ procedentes de Porto Alegre, $69, \%$ faziam acompanhamento prévio no HCPA, com mortalidade acumulada de $18,9 \%$, com tempo médio de aparecimento dos sintomas de 19,9 dias. Após o atendimento inicial, 13,7\% foram internados via emergência, $10,6 \%$ foram liberados com prescrição terapêutica e $25,4 \%$ foram referenciados ao especialista. Entre os pacientes do grupo2, a média de idade foi de 57,9 anos, 59,1\% eram do sexo masculino, $63,3 \%$ de pacientes procedentes de Porto Alegre, 27,3\% faziam acompanhamento prévio no HCPA, com mortalidade acumulada de 54,5\% e tempo médio de aparecimento dos sintomas de 82 dias. Após o atendimento inicial, 33,3\% foram internados via emergência e $38,1 \%$, referenciados ao especialista. Conclusão: Observou-se uma demora na busca por atendimento entre pacientes que não possuíam diagnóstico prévio de neoplasia, além de uma muito elevada taxa de mortalidade nesse grupo na comparação com os pacientes oncológicos já em acompanhamento (2,9 vezes). Postula-se que limitações no acesso a ambulatórios de especialidades e aspectos sócio-culturais estejam retardando e busca de atendimento em saúde e agravando o prognóstico de das doenças neoplásicas em nosso meio.

\section{Referência:}

Hamerski, S.; Hoppe, P.; Hoffmeister, E.; Azeredo-Da-Silva, A.L.F.;. Elevada mortalidade entre pacientes com diagnóstico de neoplasia estabelecido em ambulatório de pronto-atendimento clínico - Estudo IMACS. In: II Congresso Brasileiro de Medicina Hospitalar - II CBMH [= Blucher Medical Proceedings, vol.1, num.5] São Paulo: Editora Blucher, 2014. p.103 DOI 10.5151/medpro-II-cbmh-103 